\title{
EQAL to the task: stakeholder responses to a university-wide transformation project.
}

Peter Bird, Rachel Forsyth, Mark Stubbs, Nicola Whitton

Manchester Metropolitan University

\section{Introduction}

UK Higher Education is going through a period of major change and institutions within it are being forced to respond. Some of those responses are evolutionary; others are revolutionary. A case study is presented of a UK university change initiative that was unprecedented in scope and scale for the institution concerned and for the sector. Following Pettigrew (1985), an account is presented of the context, content and process of change. Using Farbey et als (1993) stratification of stakeholders, a summary is provided of different stakeholder perspectives and, following reflection, some lessons learned are offered to those contemplating change on a similar scale.

\section{Research Design}

This article is based on documentary evidence and interview data gathered from a number of sources during the course of the EQAL programme. These include:

- stakeholder interviews conducted by two independent consultants within the first year of the curriculum change (Smith and Lessner, 2012);

- evaluation data from the JISC SRC project which included interviews with students about their perspective on curriculum input (Bird et al, 2012);

- internal documentation such as emails, minutes of meetings and proceedings of internal conferences.

\section{Context for the Change}

In 2009, Manchester Metropolitan University (MMU) was the largest campus-based undergraduate university in the UK, with a total student population of more than 37,000 . It offered over 1,000 courses and qualifications, the majority of which had a strong professional bias. Like many similar UK institutions, it had evolved through a series of mergers and expansions over many decades to become a large and diverse organisation teaching a wide range of subjects across several campuses. About half of its annual budget was devolved to its eight faculties, with administrative, financial, estate, student support, library and technical services managed centrally.

Impetus for change came externally from government policy that was seeking to make students more informed consumers of higher education (Browne, 2010). The senior team and the University's Board of Governors were keen to see improved performance against external measures of student experience. Despite a genuine and sustained commitment to enhancement, and many small adaptations to policies and procedures, there had been, between 2005 and 2008 (Unistats, 2014), no substantive improvement in National Student Survey (NSS) outcomes or other measures of student experience such as progression rates. The Deputy Vice-Chancellor Student Experience (DVC SE) was given Executive-level responsibility for transforming this situation. 


\section{Articles}

At the time, the DVC SE was overseeing two projects that would ultimately become very significant for the change initiative:

- The first was a four-year project funded by the JISC (Joint Information Systems Committee) as part of its Curriculum Design and Delivery programme. The Supporting Responsive Curricula (SRC) project was established in 2008 to investigate, for four pilot areas (Law, Accounting and Finance, Physiotherapy and Creative Digital), how the institution could be made more responsive to the needs of various stakeholders, particularly students, employers and professional bodies. Workshops involving a wide range of university staff and representatives of the Students' Union were convened to explore how the University could better meet stakeholders' expectations. Cornford and Pollock (2003) have described the importance of lateral relationships in university organisation (between professional and academic staff and between staff and students) as well as the significant role of campus systems in facilitating these relationships. The workshops were set up to explore these links explicitly. They revealed complex interdependencies and varied practice specific to campuses, disciplines and cohort characteristics. This complexity and variety made it almost impossible to propose any kind of standardisation of good practice to address specific areas of student dissatisfaction.

- The second was a wide-ranging review of the institution's learning technology platform; a review which sought to draw lessons from use of the previous system and developed, through focus groups with students and staff, scenarios for an improved situation. Meetings with students revealed a desire for consistency in information provision and a set of unmet information needs: students were finding it difficult to navigate their courses and expected better information, for instance on when work was due, when classes were scheduled, which books to buy and how to contact tutors. They also expected to be notified in reasonable time of any changes to their teaching or assessment schedules (Lrt.mmu.ac.uk, 2010).

At the same time, colleagues in the Science and Engineering faculty undertook a detailed analysis of the NSS results, an exercise which revealed that students' responses to questions in the category of 'organisation and management' were having a strong negative effect on overall satisfaction, as measured by Question 22 in the survey (Fielding et al, 2010). The Dean, who also had Pro-Vice-Chancellor level responsibility for Curriculum Innovation (PVC Cl), worked closely with the analysis team and formed a strong view that organisational complexity was a limiting factor for the 'organisation and management' score.

After the PVC Cl discussed with the DVC SE his conviction that "complexity was difficult to organise", the DVC SE challenged a diverse group of staff present at an SRC workshop to identify what would need to change for a step-change improvement in student experience for the whole institution, not just the four pilot areas, and asked them to highlight any barriers to that change. Discussions revealed that complexity of the curriculum structure was at the root of many of the difficulties experienced by staff and students and was causing increased work for administrative and academic staff and dissatisfaction amongst students. Participants identified quality assurance processes as a constraint on course development: whilst these processes were considered robust and safe in relation to standards, they required a huge amount of work from administrative staff. Course leaders described how they had become experienced in producing paperwork which conformed to 'standard' 
requirements yet still enabled enormous diversity in the organisation of provision. The SRC project baseline report (Johnson and Bird, 2009) reported broad agreement that curriculum change was needed, but that this was hampered by:

- overly bureaucratic processes;

- competing demands on staff;

- conflicting time cycles in different parts of the University;

- unclear lines of responsibility for curriculum change;

- lack of sense of personal ownership;

- inertia, owing either to the scale of the task or to the existence of long-established and effective 'work-arounds' in some areas.

In summary, key drivers within the context for the change initiative can be identified as:

1. pressure from the highest level for a step-change improvement in external measures of the student experience in response to the UK Government's "informed HE consumer" agenda;

2. regular discussion with students, at both faculty and institutional (Students' Union) levels, which highlighted the need for consistency in information about content of modules and in associated assessment methods;

3. open comments from students in the National Student Survey which indicated clearly what kinds of changes they would welcome;

4. two senior leads, the DVC SE and PVC Cl, who felt that course organisation and management had become unnecessarily complex and were having negative impacts on the student experience and on the time academic staff had for their students;

5. emerging internal recognition that step-change improvement required carefullyorchestrated, systemic change.

\section{Content of the Change}

In spring 2010, with top-level support and direction from the DVC SE and PVC Cl, the University set up the EQAL Programme - "Enhancing Quality and Assessment for Learning". The goal was to make a step-change improvement in student satisfaction by refreshing the entire undergraduate curriculum whilst simultaneously re-engineering administrative processes and creating a seamless personalised experience that wrapped the University's information and online resources around each learner. In short, EQAL set out to:

transform the quality of academic life by

- simplifying structures and processes;

- delivering integrated organisational support;

- delivering a seamless, personalised student experience;

- reforming and streamlining quality assurance processes.

The ambitious deadline was to deliver a brand new, technology-supported first year for September 2011, with the new second year starting September 2012 and the new final year September 2013.

The change programme was organised as four major work strands, coordinated by the University's new Business Improvement Team. Scoping began in February 2010, with a 


\section{Articles}

benefits-mapping exercise in which each strand identified high-level benefits, outcomes and interdependencies. Work proceeded quickly to map project outcomes on a timeline that would deliver a new first year for September 2011. The need for ground rules for a new curriculum was identified as the first major deliverable (D1) and was taken in response to continued student feedback that there were too many assessment points - up to twenty in a year for some students. After consultation with student representatives and faculties, the PVC Cl proposed a new undergraduate curriculum framework that changed the size of undergraduate modules (from twenty to thirty credits), set limits on, for each module, the number of learning outcomes (max. five) and summative assessments (max. two) and limited the amount of optionality in level 4. Finally, a new set of graduate outcomes and guidance for embedding employability was included in the curriculum planning.

In June 2010, Academic Board, the University's principal academic decision-making body, approved the new curriculum framework. The implication of the Board's decision was that every undergraduate module had to be re-written, reviewed, approved and set up in supporting systems. With over 800 modules in each year of study, the scale of the task was daunting. The changes would affect every undergraduate tutor and every member of administrative and support staff who worked with them - an unprecedented level of change for the institution. The challenge was compounded by the existing system of drafting module specifications in Microsoft Word, critiquing paper copies at review events and then manually entering relevant data from the specifications into all the computer systems that needed them, such as student records, timetabling and library reading lists. A new system to capture and upload module information was identified as the second major deliverable (D2).

Rapid prototyping produced a module capture form that allowed only data entry which complied with the new curriculum framework (i.e. it had space to specify five learning outcomes and two summative assessment elements) and validation rules were added to ensure constructive alignment of assessment strategy and intended learning outcomes (i.e. the form would not submit without an explicit mapping of how the assessment elements covered each of the learning outcomes).

The third major deliverable (D3) was a revised module-approval process that could accommodate appropriate scrutiny and approval of over 800 modules simultaneously. The process incorporated specialist input from the Library and Centre of Excellence in Learning and Teaching (CELT) and took advantage of the module capture form's automatic validation rules (i.e. to ensure constructive alignment of assessment with intended learning outcomes) to establish a workflow that included Standing Panels for internal and external scrutiny and sign-off by external examiners. These Standing Panels were also to include student representation.

The fourth major deliverable (D4) was personal timetables. Staffing for the university's timetabling function was increased, the full suite of Scientia timetabling software was installed and faculty timetabling champions were identified to coordinate collection of planned teaching activities for the new modules.

The fifth major deliverable (D5) was consistent rollout of the assessment handling functionality in the student records system so that became a central, definitive source of all assessment information for the university. 
The sixth major deliverable (D6) was standardisation of the support students would receive from face-to-face information points across the university.

The seventh major deliverable (D7) was a Core+ VLE for all programmes and modules with new advisers to support embedding technology-enhanced learning in the curriculum. Based on Moodle, the Core+ VLE was driven by the student records system and aggregated data from a range of other systems (such as coursework submission deadlines, library reading lists, provisional marks, past examination papers and a personal timetable) to ensure that each student received a seamless, personalised online experience. A companion smartphone app was subsequently developed.

The eighth major deliverable (D8) was academic engagement with all the other deliverables to design, prepare and deliver the new undergraduate curriculum.

The ninth major deliverable (D9) was a revised, data-driven, continuous-monitoring improvement process and supporting system to ensure the step-change was followed up with continuing improvements.

The tenth major deliverable (D10) was a student engagement monitoring process and supporting system to facilitate interventions for improving student retention, progression and success.

In summary, the key content of the change comprised:

1. refreshed and standardised undergraduate curriculum

- D1 New curriculum framework

- D2 New module capture system

- D3 New Standing Panels for module approval

- D8 Design, preparation and delivery of new undergraduate curriculum

2. seamless, personalised student information

- D4 Personal timetables

- D5 Centralised assessment handling

- D6 Standardised face-to-face support

- D7 Core+ VLE and Technology-Enhanced Learning Advisors

3. fit-for-purpose management information

- D9 New data-driven Continuous Monitoring and Improvement process

- D10 New Student Engagement Monitoring process

\section{Process of the Change}

The EQAL Programme was established as a top-down change initiative championed by the DVC SE and managed through monthly board meetings attended by the $\mathrm{PVC} \mathrm{Cl}$, the Registrar, the Director responsible for library, IT and technology-enhanced learning, a PVC without portfolio (who provided senior support to particularly challenging areas, such as personal timetabling) and leaders of the four key work strands. The EQAL board and strand leaders received programme and project support from the Business Improvement Team (e.g. tracking benefits, risks, expenditure, progress, deliverables and interdependencies). Strand leaders already had management responsibility for the area concerned (e.g. Head of Quality, Head of Technology-Enhanced Learning, Head of Planning and Management Information, Assistant Registrar) and convened networks of contacts appropriate to the 


\section{Articles}

delivery of their particular deliverables. As key champions for EQAL, the DVC SE and PVC $\mathrm{Cl}$ provided face-to-face briefings in faculties and met with Trade Union representatives.

Four case studies were set up to pilot particular employability developments in Law, Physiotherapy, Accountancy and Finance, and Digital Marketing. The leaders of these case studies worked with students and staff to develop specific initiatives to embed employability into the curriculum.

Initially, many academic and administrative staff were sceptical about the change to thirty credits and concerned about the impact on individual workloads and academic freedom: some tutors expressed the view that thirty-credit modules forced them to combine curriculum areas which they felt should be separate; others felt constrained by the limited number of assignment elements, which they feared would compromise their ability to stage support and teaching effectively. Trade Union representatives were concerned about workload and a hidden agenda of curriculum rationalisation leading to workforce reduction. The DVC SE and PVC Cl explained the rationale for change and sought to clarify that the change was about making more time available for students, not reducing headcount, and tried to be clear about which items were open for consultation and which were fixed.

To ensure strong communication with faculties, EQAL champions were identified in each faculty to cascade project information, track progress on the ground and provide a sounding board on faculty opinion. The champions revealed the dominant concern to be about workload, as tutors worried about delivering the old curriculum whilst simultaneously developing the new against very tight completion and review deadlines. Concerns about the locus of decision-making were also present, with one faculty champion reporting that "[a]cademics were not opposed to the principles of EQAL, but they felt that they weren't always part of the decision-making and discussion." (Smith and Lessner, 2012). Some academic staff were also sceptical about the ability of central services to deliver the promised systems (module capture forms, timetabling and Core+ VLE) in time for them to prepare their new teaching. These concerns were fed back to the EQAL Board and events, demonstrations and briefings were held to reassure colleagues that the project was on track and a 'Learning and Teaching' conference, organised to support EQAL, became an annual feature.

Sensitivity to workload impacts was factored into system and process-design decisions. For instance, the original multi-page module specification was cut down through consultation and rapid prototyping to a bare minimum single page. Seeking ways to minimise any burden introduced by new working methods was a feature of the EQAL change process and this always included inputs from a wide range of relevant stakeholders to ensure a $360^{\circ}$ view of the process was considered.

New staff recruited to support timetabling and the Core+ VLE provided key contact points between the faculties and central services, which was very important as EQAL's data-driven approach to providing students with personalised information placed a new emphasis on ensuring that central systems matched the situation on the ground in faculties. Encouraging growing awareness of the need for faculty activities to be reflected accurately in central systems was a key characteristic of the EQAL change process. 
Another characteristic was regular effort to highlight tangible signs of progress: internal newsletters, a blog and staff briefing events were used to remind staff of significant achievements, such as approving over 800 modules on schedule or over 30,000 students engaging immediately with the new Core+ VLE.

A feature common to all the deliverables has been the notion of programme and module leader ownership: the module capture form was designed for module leaders; the Core+ VLE has been set up to reflect module and programme leader roles automatically and the new Continuous Monitoring and Improvement system is designed to reinforce the role of module and programme leaders in the quality enhancement process. The notion of reinforcing module and programme leader ownership through major deliverables has been an important part of the EQAL change process.

In summary, the EQAL change process sought to:

- demonstrate obvious support from the highest level;

- use professional programme and project management to maximise chances of delivery;

- improve project-faculty communication through designated EQAL champions;

- involve students throughout the process at both faculty and institutional levels (Students Union) through a partnership approach;

- respond to concerns about workload by minimising the burden imposed by deliverables;

- respond to concerns about feasibility through regular demonstrations of progress;

- encourage accurate reflection of faculty activities in central systems;

- reinforce module and programme leader ownership for quality of provision.

\section{Perspectives on the Change}

Like any university change process, particularly one involving major curriculum change (see, for instance, Hannan and Silver, 2000), some stakeholder views will be positive, some will be negative and many will change over time. Independent interviews undertaken with a range of EQAL stakeholders in 2012 reflected the beliefs, emotions and aspirations of those caught up in the throes of a significant, but as yet incomplete, process of change.

Perceptions captured were inevitably coloured by role, ability to see the wider picture and the degree of impact EQAL had on their working practices - for some, a sense of frustration and loss of control was predominant; for others, there was a feeling of relief at having achieved goals on the edge of possibility. Overall, there was a broad understanding and acceptance of the aims of the initiative and satisfaction in working together to achieve an improved student experience. To give a more complete account of the EQAL change initiative, key findings from those interviews are presented using Farbey et als (1993) stratification:

- Strategic Apex: Directorate / Executive

- Middle Line: Heads of Department

- Operating Core: Academics

- Champions: EQAL Faculty Champions

- Support Staff: Administrators

- Technostructure: IT/TEL etc. 
- Students - the recipients of the changes

This staff perspective is complemented by views from the student perspective in quotes from the student union and an overview of changes in external student experience data.

\section{Directorate / Executive Perspective}

Although the context for the change was pressure from the Board of Governors for an immediate step-change improvement in external measures of student experience, the DVC SE regarded EQAL as a fundamental, systemic intervention:

“... a multi-faceted and medium-term project” DVC SE

Even under considerable and high-level pressure to show immediate gains in student satisfaction with course organisation and management, the DVC SE reminded the EQAL Board at regular intervals that tackling these 'hygiene factors' was a precursor to making more academic time available for activities with real academic value, such as formative feedback. He also stressed that the programme had to strike the right balance between ambition and feasibility:

"The process has been evolutionary as much as revolutionary ... it unfolds as ... firstyear students progress on through their degree programmes" DVC SE

Executive members of the EQAL Board were also keen to stress that the intention was not to stifle academic creativity, exercise control over academics or initiate significant re-structuring and reduction of academic staff. Standardisation and automation of processes were clear aims, but so was recognition of the need for academic decisions to be made by programme teams within the new curriculum framework (of thirty-credit modules and two assessment elements):

"We needed a greater degree of standardisation and consistency about the way the curriculum was assessed. We stress, however, that creativity remains important; the university is noted for the quality and variety of assignment types and we don't want that to change. Academic staff are in charge of their own destiny and retain control over the planning and delivery of the curriculum" PVC CI

\section{Head of Department Perspective}

Heads of academic departments and central services played an important role in ensuring their staff were able to engage with the EQAL changes. Key service heads were involved directly as strand leaders in the EQAL Board structure and offered a unique perspective on the changes, the way they had been coordinated and their impact on staff and students:

"EQAL bundled a number of changes together and gave them momentum. Taking issues to the EQAL Board was helpful because it meant that decisions were made by, and had the backing of, a key group of senior staff." Deputy Registrar

"Most disagreements occurred over deadlines which had to be imposed because of the interlocking nature of the different strands of the initiative. ... You needed to be clear in your own mind where you could be flexible and where you couldn't, then be 
completely honest with the faculties concerned... More and better communication would be my watchword if I were to do this again." Head of Quality

Heads more closely involved with EQAL shared the DVC SE's view that it was a mediumterm programme laying important foundations for the future:

“When the institution has full oversight of each programme's and [module's ] performance, it will become easier to identify key trends or themes, and plan strategically." Head of Quality

\section{Academic Perspective}

At the start of the process, academics had been suspicious about EQAL, fearing a stifling of their own creativity but also suspecting that the university would use the programme as an opportunity to reduce the number of taught modules and consequently engineer a staff reduction (Braverman, 1994). The trade union in particular voiced a strong anti-EQAL message when the programme was first announced:

"UCU finds the proposals, as currently described, unacceptable as they could potentially result in changes to the terms and conditions of some academic staff and potentially have a serious impact on staffing levels and they do not establish a sufficient reason for the changes that are being suggested" UCU representative

Although the EQAL proposals had been crafted to address issues which academic staff had identified as problematic during initial workshops (e.g. that the quality assurance system was too labour-intense and cumbersome and that tutors would also like to see NSS scores improve to reflect hard work and commitment which was sometimes undermined by University systems that weren't student-friendly), the DVC SE and PVC CI had to work hard to reassure academics that EQAL would tackle these issues directly while retaining academic decision-making in programme teams. Their efforts were not always successful, and with 1,500 academic staff, it was sometimes difficult to reach everyone. However, module leaders overcame initial scepticism and used the module capture forms to enter over 800 modules each year. Presentations from fellow academics involved in early pilots helped to make the case for engagement: for instance, the mostly positive view given by a tutor about his experience of piloting over summer 2010, particularly that the form had not stifled his creativity, helped convince colleagues to enter their modules.

\section{EQAL Faculty Champion Perspective}

As key communication points between the EQAL programme and faculty academics, the EQAL Champions provided a rich perspective on the change initiative.

Many tutors were sceptical about the module size of thirty credits and felt it too inflexible, which was also a view held by some of champions:

"I don't like the 30-credit unit size; it's too big and prevents a diverse curriculum, reduces student choice and requires lumping things together which don't naturally fit." EQAL Faculty Champion 
Concerns about the impact on workloads of absorbing the EQAL activities on top of existing responsibilities were particularly strong and some questioned whether the timescale had been too ambitious:

"Lecturers who have high teaching loads, and consequently a large volume of marking, they would have a large number of [modules] to re-write for EQAL at the same time as teaching and marking to undertake their normal workload. This has created a lot of pressure on tutors." EQAL Faculty Champion

"The workload was considerable for everyone and impinged on periods of leave. It also coincided with the new timetable regime and the continuous improvement plan (CIP). The time frame meant that staff were under considerable pressure.... People support the idea of EQAL but were not given the timeframe to do it properly... The timing undermined what might have been a better process." EQAL Faculty Champion

However, many staff recognised considerable benefits in the EQAL changes:

"... reducing summative assessments to two, where some may not initially like it, it means using a better variety of assessment types, better use of formative assessments and different methods of assessment. The requirement is for two summative assessments so teams can be more creative with formative assessments."EQAL Faculty Champion

There was also gratitude for the support provided by CELT and the new TechnologyEnhanced Learning Advisors in designing and subsequently implementing the new modules.

In terms of embedding employability skills, the process supported programme teams to embed employability explicitly, leading to a number of enhancements for students. For instance, in Law, students have been able to take up more pro-bono opportunities than was previously the case:

"...the increased involvement of the legal profession, both in providing placements and in attending at more practitioner talks facilitates the students' experience as it gives students greater confidence that they are equipped to enter the profession through their increased familiarity with it" EQAL Faculty Champion

\section{Administrative/Support Perspective}

Administrators through the institution were affected by the change, but those involved with quality assurance processes saw unprecedented work peaks as several hundred modules came forward for review simultaneously:

"I often worked over my scheduled hours. I don't think anyone envisaged at the outset just how much work it would actually cause." Faculty Quality Administrator

However, administrative staff also recognised the benefits their hard work would bring for students:

"... It is also beneficial for students who will have a standard experience across the institution. Faculties are now part of one institution; previously, crossing faculties in 
your choice of [modules] could have felt as if you were changing institutions." Faculty Quality Administrator

And senior colleagues identified a fundamental shift in focus in the approach to quality:

"I think the major driver for the Academic Standards and Quality Enhancement team has been the potential to improve the student experience. Before 2010, there was considerable variation from [module] to [module] in the assessment burden placed on students (and therefore on staff). Now we have a standard of two assessments per 30-credit [module] in the new Undergraduate Curriculum Framework. We also needed to reduce the impact of burdensome processes on academic staff so that they could spend more time creating a positive learning experience for students." Head of Quality

Those involved in pedagogic support found new interest from academics in revisiting academic practice as they redesigned their modules:

“... there is a bit of a buzz about assessment at the moment. People are asking us if we are assessing students in the most appropriate way. [EQAL] helps us think about assessment as an ongoing rather than just a summative activity' Senior Lecturer, CELT

\section{IT/TEL Perspective}

Delivering a seamless personalised student experience required datasets to be gathered from a number of different computer systems so they could be "wrapped around the learner". For everything to be aggregated, those datasets had to be complete and tagged consistently with student, programme and module codes. Completeness, accuracy and consistency of data required academic and administrative colleagues to build an understanding of how the information they entered affected the student experience:

"There is a better understanding now of the connection between basic aspects of the curriculum and the student experience... it doesn't matter how good teaching and learning is, it will be dragged down if the basics aren't in place, like knowing where you are supposed to be, what assignments will be set and when the submission dates are. I think that understanding of this is beginning to grow across the institution now." Head of Department, Learning \& Research Technologies

The Core+ VLE had been shaped very strongly by students' information needs and it was particularly pleasing to see the take-up, not just for accessing study information and undertaking assessment, but also for collecting feedback on students' experiences of their programme and modules:

"[The Core+ VLE] instantly became a great success, with the site getting over 400,000 hits a day at its peak. Further proof of students' enthusiasm was their response to a survey on what they liked best about their studies and what didn't work as well: more than 10,000 took the trouble to reply, leaving nearly 60,000 comments!' Head of Department, Learning \& Research Technologies 


\section{Student Perspective}

With a population of over 37,000 students, it is challenging to capture the diverse ways in which EQAL changes will have been felt, so this section presents views from Student Union representatives, quotes from individual students and a summary of changes in student experience data ante and post EQAL. Reflecting the partnership culture of the project, students were consulted in a variety of ways: through direct contact between student representatives and members of the EQAL board, focus groups and individual interviews, as well as through follow-up surveys after attendance at employability events.

The Student Union representatives recognised both the rationale and scale of the project:

"I appreciate why MMU has done EQAL - for a more positive student experience. These things just take time; it's such a big university. On the whole, the university does listen to the student voice." Vice President, Student Union

They noted how decisions taken with EQAL had been informed by real student experience:

"I sit on different committees within the university. We talk about the timetable changes, for example. The Student Union does a lot of research... some of our research has informed the EQAL process - for example, on timetabling." Vice President, Student Union

Although Student Union colleagues were aware that the Moodle Core+ VLE had been designed in response to scenarios for an enhanced student experience, they were surprised by how quickly the student community adopted Moodle:

"Moodle is now used uniformly and has been a big success. It was unexpected to see how successful Moodle was. All information students need about their course is now available [on Moodle]." Vice President, Student Union

Embedding employability activities more explicitly into the curriculum was also popular with students:

"We've met a lot of people in the industry so [we're] getting our name out there and getting all their details, being able to email our CV's and seeing if there's any jobs. Networking is very important at this stage." Third-year student

Whilst personal timetabling and new modules were introduced a year at a time, Moodle was rolled out to all years in September 2011 and aggregated as much study information as possible: deadlines, provisional marks, reading lists, past examination papers and course timetables if personal ones weren't available.

"...they've made so many changes to the timetable now it's so much better, so I think they listened to us over the past two years" Third-year student

“...they've changed like the actual times of lectures to fit round people when they can't get there" Third-year student

This meant that impacts of EQAL could be seen in National Student Survey results from 2012 onwards. 


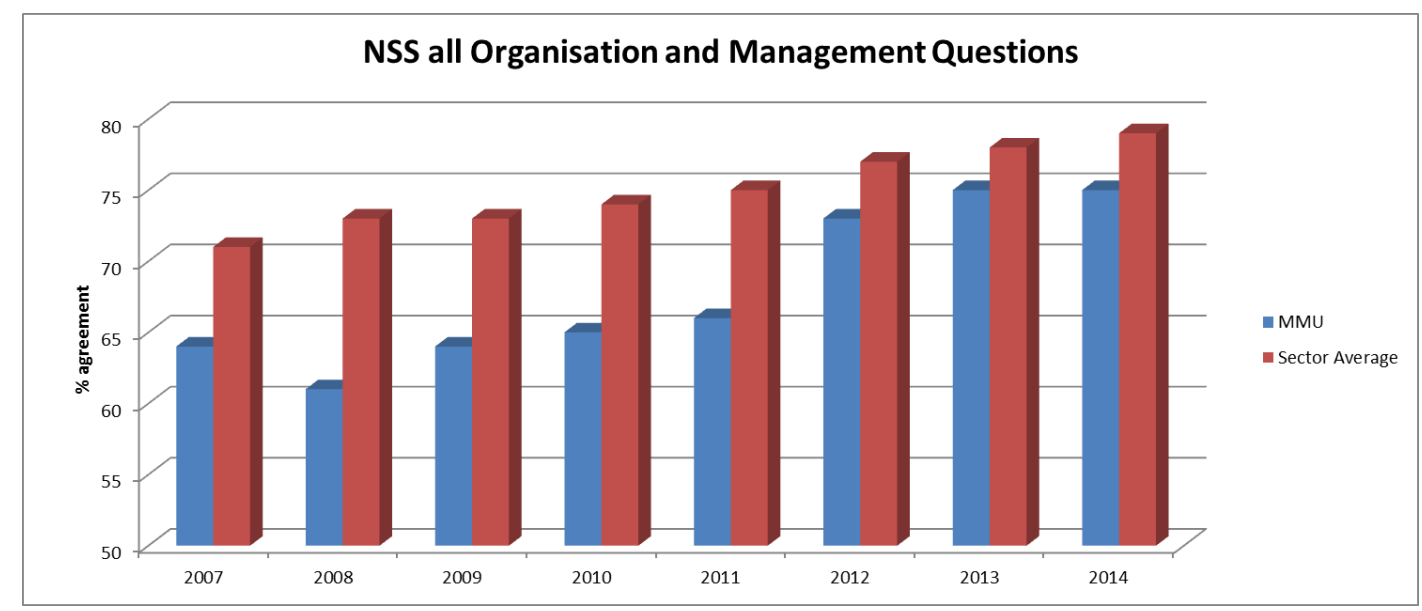

The chart reveals a marked improvement in scores for the Organisation and Management aspect of the NSS post EQAL.

Changes in the areas targeted by EQAL are as follows:

- NSS 2012: organisation and management up 7\%; assessment up 6\%; learning resources up 6\%; overall satisfaction up $6 \%$

- NSS 2013: organisation and management up $2 \%$; assessment up $2 \%$; learning resources up 1\%; overall satisfaction up 3\%

- NSS 2014: organisation and management no change; assessment up 1\%; learning resources up $2 \%$; overall satisfaction down $1 \%$

\section{Reflection and lessons learned}

The scope, scale and pace of the EQAL change was unprecedented for MMU and the EQAL Board has asked that a formal evaluation be carried out to reflect on what has been achieved and draw lessons learned. Neither EQAL nor its evaluation are complete, so these reflections and lessons learned are only initial observations.

The first observation is that large-scale change with the scope, scale and pace of EQAL is possible and can make a significant difference to external performance indicators. Ante EQAL, MMU was considered to be a conservative organisation, but, post EQAL, there is now confidence that the institution can make large-scale change. EQAL has also demonstrated to the sector that such large-scale change is possible.

In many ways, the process adopted for EQAL attempted to follow good practice: the Business Improvement Team supported a programme and project management approach that had regular and obvious support from key senior staff; key departmental heads were selected to deliver change in their areas of responsibility; project champions provided an important link between the project and stakeholders on the ground; project deliverables were designed and adapted in response to stakeholder feedback and were deliberately designed to reinforce local ownership of the quality of data, programmes and modules. Like most programmes, communication could have been more effective, particularly to dispel myths that formed about the constraining nature of the new curriculum framework.

Whilst formal evaluation may shed new light, specific critical success factors for EQAL at this stage appear to be: 
1. Understand important dynamics

The EQAL change initiative was guided by a clear understanding that failure to address poor performance in external measures of student experience would become a major problem as the link between reputation and resources became stronger.

2. Set high-level goals

The Benefits Management approach adopted when planning and scoping EQAL focused attention on a key set of high-level goals, such as enhanced NSS satisfaction, which have subsequently been used to track progress in terms of realising intended benefits.

3. Understand where change is required

Detailed analysis of the NSS and findings from student focus groups focused attention on consistent delivery of a 'seamless, personalised online experience' that improved perceptions of course organisation by 'wrapping study information around the learner'.

4. Leave academic decisions to course teams

EQAL deliverables were targeted on a framework in which course teams could express their creativity and expertise to create new modules and new learning, teaching and assessment experiences. For instance, the module capture form was precise about mandatory information but did not prescribe how course teams would deliver the module.

5. Be bold and plan holistically

Workshops pre-EQAL were quick to spot the interdependencies between curriculum, processes and systems, but, rather than submitting to holistic paralysis ("we can't change anything because we'd have to change everything"), EQAL took the bold step of proposing simultaneous change to all areas as each could not be tackled alone.

6. Involve stakeholder groups especially students

The institution implemented processes that involved stakeholder groups at every step of the change. At both faculty and institutional level, a strong partnership approach was maintained with students, keeping them informed of changes but most importantly demonstrating that their feedback was being incorporated into new systems and processes.

7. Ensure you've got the right team to drive Monthly meetings of a board comprising the DVC SE, PVC CI, Registrar and a Director of key services ensured that major decisions could be taken quickly. The choice of key departmental heads to lead work in their areas of responsibility ensured that EQAL was prioritised and embedded appropriately and was informed by real understanding of the challenges and dependencies.

8. Make 'big asks' as small as possible

Stakeholders' concerns about the workload arising from trying to design a new curriculum while delivering the current one meant that EQAL deliverables really had to minimise the burden they placed upon academic and administrative colleagues. Asking only once for the bare minimum data set was an important design criterion.

9. Make it stick by reinforcing change

The EQAL Board was aware that the initial step-change improvement needed to be followed up with continuous, reinforcing change to realise the intended benefit of an improving student experience. Systems designed to provide seamless, personalised 
data were also designed with a view toward continuing collection of learning analytics data to drive continuous improvement, which was the final deliverable that made up the content of the core EQAL changes.

In many ways, these nine observations resonate with Kotter's eight steps, although Kotter's first four steps are more explicit about building a shared vision for the change (Establish sense of urgency; Create guiding coalition; Develop a change vision; Communicate vision for buy-in). Greater attention to this with faculty stakeholders may have helped to address some of the communication problems noted in the case study.

Accounts of the institution's experiences through this major change will be of significant benefit to the sector. Recent findings by Christensen and Eyring, that change is much more palatable to the university community when 'the innovation emphasis is on quality rather than mere cost reduction' (Christensen and Eyring, 2011, p.387), resonate with the experience of EQAL. Despite reservations about the timing and purpose of the EQAL programme, stakeholders embraced the goal of improving the student experience and tangible, university-wide results were seen. The management promise that this was not a subtle staff reduction exercise held true.

\section{Reference list}

Bird, P., Forsyth, R. and Whitton, N. (2012) Supporting Responsive Curricula: Final Evaluation Report. Available at:

http://www.jisc.ac.uk/media/documents/programmes/curriculumdesign/SRC_Final_Evaluatio n_Report.pdf (Accessed: 25 August 2014)

Browne, J. and Great Britain. Department For Business, Information And Skills. (2010) Securing a sustainable future for higher education : an independent review of higher education funding and student finance. London: Department for Business, Information and Skills.

Braverman, H. (1974) Labor and monopoly capital: The degradation of work in the twentieth century. Monthly Review Press.

Cornford, J. and Pollock, N. (2003) Putting the University Online: Information, Technology and Organizational Change. Abingdon: Routledge.

Christensen, C. and Eyring, H. 2011. The innovative university: Changing the DNA of higher education from the inside out. New York: Jossey-Bass.

Department For Business Innovation And Skills (2011) Higher education: students at the heart of the system. Stationery Office.

Farbey, B., Land, F. and Targett, D. (1993) How to Assess your IT Investment: A Study of Methods and Practice. Oxford: Butterworth-Heinemann.

Fielding, A., Dunleavy, P. J. and Langan, A. M. (2010) "Effective use of the UK's National Student (Satisfaction) Survey data for science and engineering subjects." Journal of Further and Higher Education, 34, 347-368.

Hannan, A. and Silver, H. (2000). Innovating in Higher Education. London: SRHE/OUP. 


\section{Articles}

Johnson, R. and Bird, P. (2009) SRC Baseline Report. Available at:

http://www.jisc.ac.uk/media/documents/programmes/curriculumdesign/srcbaselinereportv1.0 .doc (Accessed: 26 August 2014).

Kotter, J.P. (1995) "Leading change: Why transformation efforts fail." Harvard Business Review 73(2), 59-67.

Lrt.mmu.ac.uk (2010) Outcome of Learning Technologies Review. Available at: http://rt.mmu.ac.uk/ltreview/2010/03/04/outcome-of-learning-technologies-review/ (Accessed: 26 August 2014).

Pettigrew, A. M. (1985) The awakening giant: Continuity and change in Imperial Chemical Industries. Oxford: Blackwell.

Smith, R. and Lessner, E. (2012) In the Throes of Change. Available at:

http://jiscdesignstudio.pbworks.com/w/file/54373376/In the Throes of Change release.docx (Accessed: 26 August 2014).

Unistats (2014) The official website for comparing UK higher education course data. Available at: http://unistats.direct.gov.uk/ (Accessed: 26 August 2014).

Watson, D. (2009) The Question of Morale: Managing Happiness and Unhappiness in University Life. Maidenhead: OUP. 